\title{
Soil Velocity Profile on Soft Soil using Seismic Refraction
}

\author{
Mohd Jazlan Mad Said ${ }^{1,}$, Adnan Zainorabidin ${ }^{2, b}$ \\ and Aziman Madun ${ }^{3, c}$ \\ ${ }^{123}$ Universiti Tun Hussein Onn Malaysia, Johor, Malaysia \\ amohdjazlan18@gmail.com, badnanz@uthm.edu.my, 'aziman@uthm.edu.my
}

Keywords: seismic refraction, soft soil, soil velocity, soil profile

\begin{abstract}
Soil velocity profile often used as subsurface characterization by using geophysical techniques. Seismic refraction is one of geophysical technique to determine primary wave (p-wave) velocity of the soil profile. In this paper, seismic refraction technique has been performed on two different types of soft soil (peat soil and Soft clay) for comparison of its p-wave velocity soil profile. From p-wave velocity soil profile comparison, its show the peat soil has soil velocity range from $211 \mathrm{~m} / \mathrm{s}-534 \mathrm{~m} / \mathrm{s}$ at depth of $0-4 \mathrm{~m}$ while the soft clay show soil velocity range from 248 $\mathrm{m} / \mathrm{s}-1842 \mathrm{~m} / \mathrm{s}$ at depth of $0-5.5 \mathrm{~m}$. The profiles of peat soils and Soft clay have been verified using peat samplers and existing borehole data. Both of velocity soil profiles, indicated that peat soil have lower velocity compare with soft clay due to its unique and soft soil characteristics. The difference of p-wave velocity soil profile between peat soil and soft clay are clearly showed both soils have different soil p-wave velocity with different soils characteristics.
\end{abstract}

\section{Introduction}

Soil velocity profile often used as subsurface characterization by using geophysical technique. Seismic refraction is one of non-intrusive geophysical technique mainly used to determine the primary wave ( $p$-wave) or compression wave velocity of the soil profile. Soil velocities are obtained from propagating seismic wave travel through the earth's interior. This seismic wave is known as body wave where consists of two different types such as primary wave and shear wave. Body wave travelling within mass cause loss energy thus contains less energy than the surface wave [1]. Seismic refraction method used primary wave that refracted at the soil layer boundary and bounced back to the surface to be capture by geophone as seismic wave first arrival [2]. Seismic refraction surveying makes use of this phenomenon to determine ground structure by observing the time taken for the energy to travel through the subsurface [3]. The velocity of the P-wave depend on different material parameters such as density, porosity, the elastic module, water content, rock type and how weathered the rock is [4].

\section{Peat Soil}

The peat soil velocity is taken at Parit Nipah, Johor. Peat soil is an organic with content more than $75 \%$, which caused a lot of problems for construction due to unpredictable behaviour of its properties. Peat soils are formed through accumulation of dispose organic plant and have been preserved under conditions of incomplete aeration and high water content [5]. It's in the category of problematic soil because having the low shear strength and high compressibility [6]. Peat soil has unique characteristics such as high water content $(>200 \%)$, high compression, high organic content $(>75 \%)$, low shear strength $(5-20 \mathrm{kPa})$ and low bearing capacity $(<8 \mathrm{kN} / \mathrm{m} 2)$ [5]. Peat poses serious problems in construction due to its long-term consolidation settlements even when subjected to a moderate load. It is generally considered that peat soil is not suitable for supporting foundations or loadings in its natural state [7]. 


\section{Soft clay}

Soft clay is known with high compressibility low stiffness and low strength to support heavy structures such as high rise building. Soft clay characteristics with high in situ water contents are vulnerable to large settlements and have low shear strength [8]. It's typically known that have variation in engineering and physical properties such as void ratio, water content, grain size distribution, compressibility, permeability and strength [9]. The soft clay velocity profile is taken at RECESS, UTHM sites. It's classified as organic clays or MH (Micaceous or Diatomaceous fine sandy or silty soils or elastic silts) [9].

\section{Methodology}

In this study, the seismic refraction equipment consists of source, detector and recorder. The source of seismic survey is $7 \mathrm{~kg}$ of sledge hammer that strike on an impact plate. For detectors, use a 24 unit of $10 \mathrm{~Hz}$ vertical geophone to detect high frequency wave from the sledgehammer seismic source for shallow depth investigation. While ABEM Terraloc MK-8 seismograph was used for the recorder for seismic raw data. For data acquisition, there are two reels of geophone cable and each reel consists of 12 geophones connector point. During setup the geophone cable, the cable was in linear or straight line to have optimum result during recording. The geophone spacing for this study is 1 meter and the geophones should be placed on clear area and approximately level with the ground. Offset distance for peat soil and clay soil are depend on the critical distance that viewed from the seismograph. The seismograph, it placed at the center of geophone array line. Fig. 1 shows the seismic refraction equipment arrangement of geophone array lines. There are seven shot point were taken at offset and intervals of $1^{\text {st }}$ and $2^{\text {nd }}, 6^{\text {th }}$ and $7^{\text {th }}, 12^{\text {th }}$ and $13^{\text {th }}, 18^{\text {th }}$ and $19^{\text {th }}$, and $23^{\text {rd }}$ and $24^{\text {th }}$ geophones as shown in Figure 2.

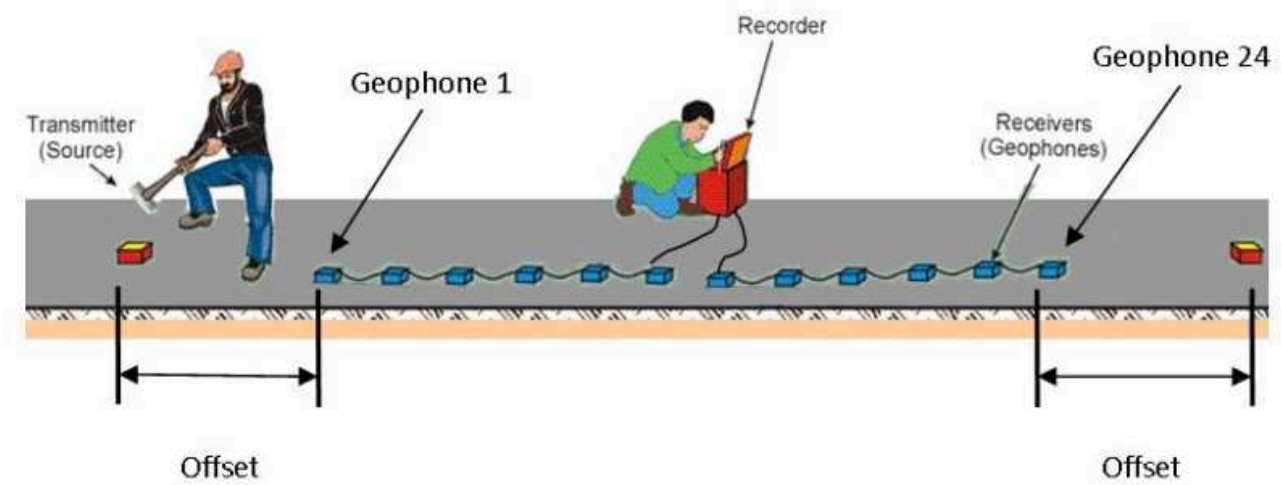

Fig. 1 Seismic refraction equipment arrangement of geophone array lines

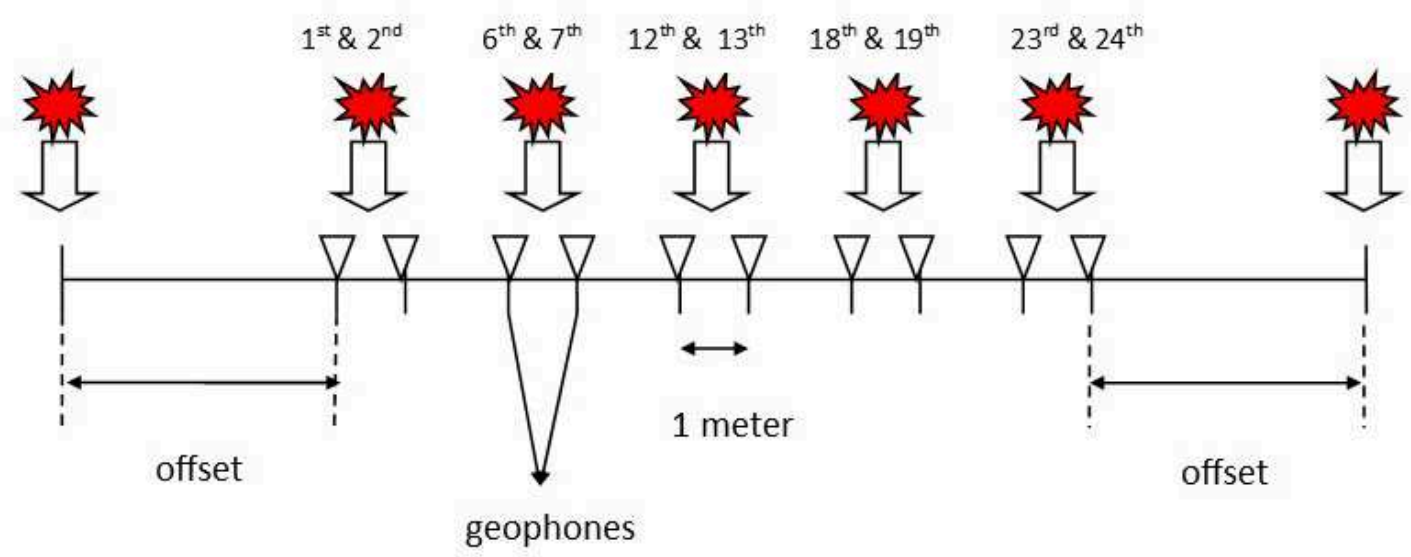

Fig. 2 Shot point locations 
The quality of seismic raw data was increased by stacking the data during data acquisition using seismograph. This allows to improve the signal to noise ratio $(\mathrm{S} / \mathrm{N})$ that's very important in seismic refraction method to observe the wave first arrival in the seismograph. Typically five times of stacking data are sufficient for seismic refraction on hard soil, but its different case for soft soil. For peat soils, it was required 15 successful blows of sledgehammer while for soft clay it was required 10 successful blows for each shot point's location. The amount of data stacking may increase because it depends on the seismic wave first arrival observed in the seismograph.

\section{Result and Discussion}

Velocity Profile of Peat and Soft clay Velocity profile of peat and Soft clay have obtained after process the raw seismic data using SeisOptPicker software and SeisOpt@2D software. Fig. 3 shows the velocity profile of peat soils while Fig. 4 shows the velocity profile of Soft clay. Both of the soil profile have been divided into several layers depend on the colour contrast which showing the difference of its soil velocity. As shown in Fig. 3, the peat soil velocity profile has divided into four layers. The first layer has a soil velocity range of $206 \mathrm{~m} / \mathrm{s}-406 \mathrm{~m} / \mathrm{s}$ indicated very soft peat soils on top layer. The velocity profile of second layer has increased slightly which show a mixed soft layer of peat and soft clay with velocity from $449 \mathrm{~m} / \mathrm{s}-684 \mathrm{~m} / \mathrm{s}$ at depth of $2 \mathrm{~m}$ until $5 \mathrm{~m}$. The velocity increased significantly where has increase two times from top layer where it's has a soil velocity range of $728 \mathrm{~m} / \mathrm{s}-1090 \mathrm{~m} / \mathrm{s}$. At a depth of $5 \mathrm{~m}$ below, the soil velocity has achieved more than $1000 \mathrm{~m} / \mathrm{s}$ which indicated a firm soil layer.

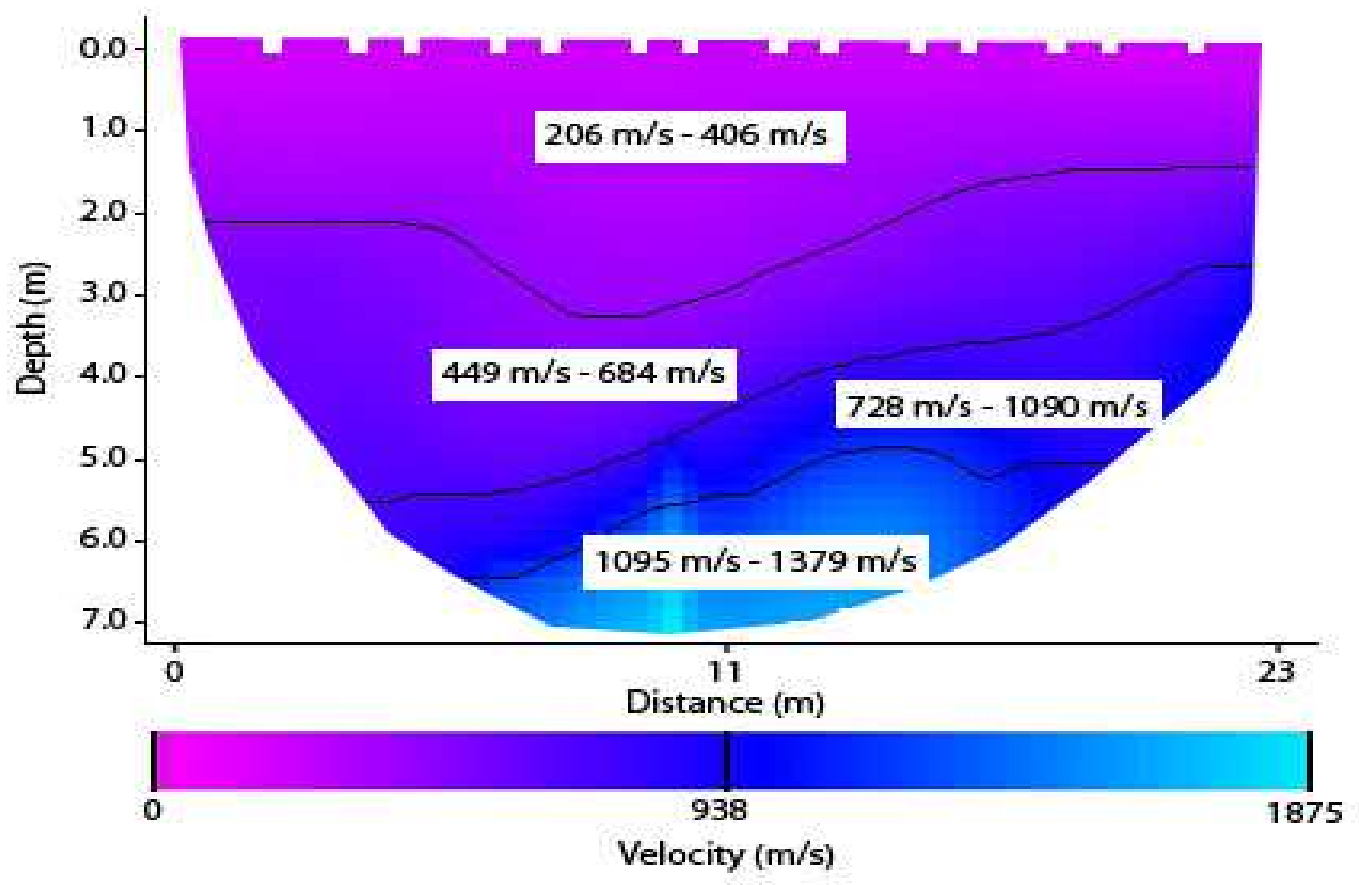

Fig. 3 Soil velocity profile of peat soil 
Velocity profile of Soft clay as shown in Figure 3 also has divided into 4 soil layer with significant differences. At top layer with depth of $1.5 \mathrm{~m}$, the soil velocity is between $218 \mathrm{~m} / \mathrm{s}-521$ $\mathrm{m} / \mathrm{s}$ which indicate this is soft layer. The soil velocity increased significantly at the second layer where at depth $1.5 \mathrm{~m}$ to $3 \mathrm{~m}$, the velocity is $603 \mathrm{~m} / \mathrm{s}-1112 \mathrm{~m} / \mathrm{s}$. The third soil layer has a firm layer with velocity $1285 \mathrm{~m} / \mathrm{s}-1772 \mathrm{~m} / \mathrm{s}$ at depth of $3 \mathrm{~m}$ until $5 \mathrm{~m}$. The bottom soil layer has velocity 1932 $\mathrm{m} / \mathrm{s}-2400 \mathrm{~m} / \mathrm{s}$ shows it has a stiff soil layer compared with top soil layer where increased about 4.6 times with top soil velocity.

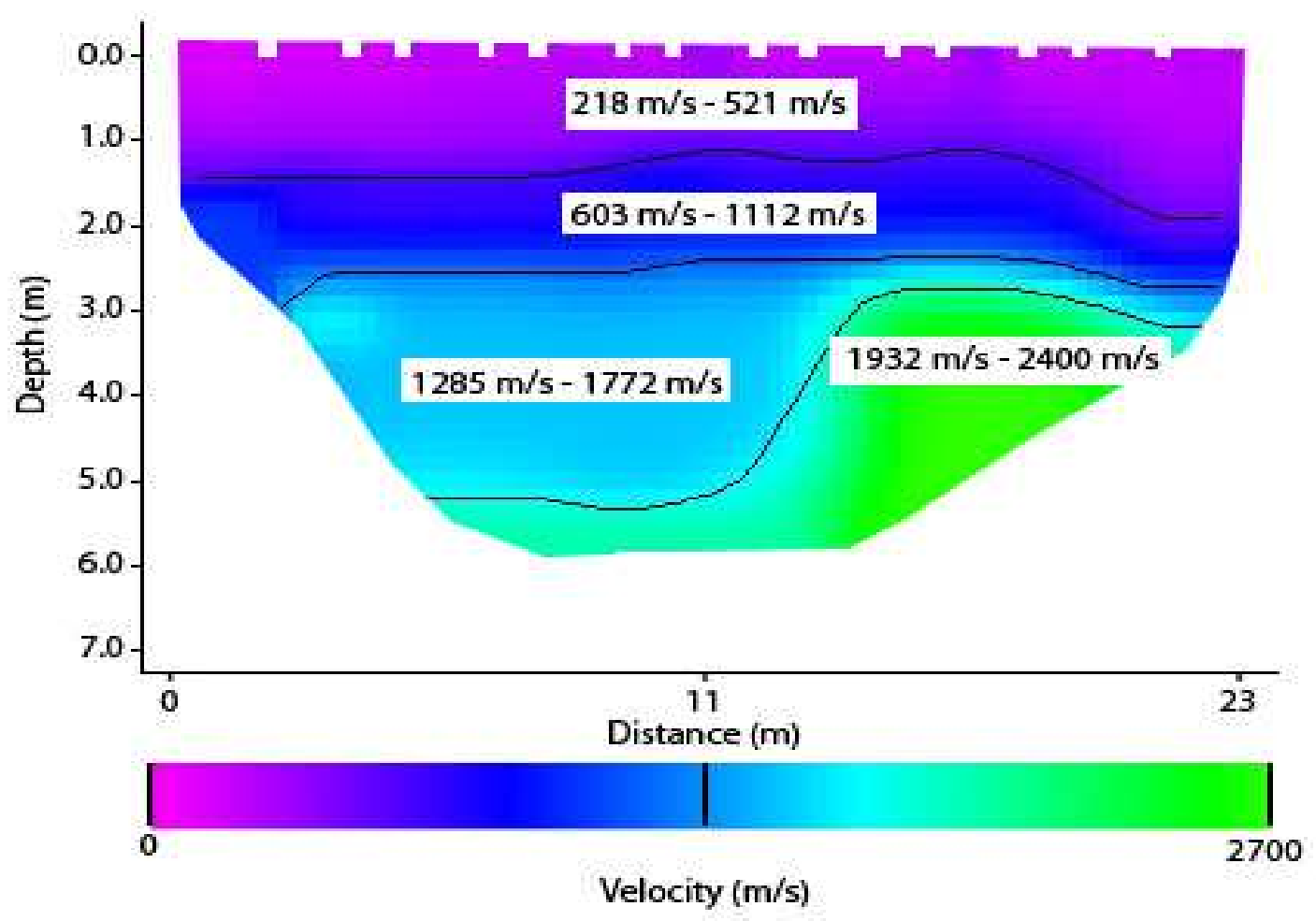

Fig. 4 Soil velocity profile of soft clay.

Soil Velocity Comparison between Peat and Soft clay From both soil velocity profile as shown in Fig. 5, there are obvious differences that can observe even though both of the soils are categorised as soft soils. For every $0.5 \mathrm{~m}$ depth, the soil velocity of peat and Soft clay are observed as shown in Table 1. From the table, there are two curves showing significant differences from top soil $(0 \mathrm{~m})$ until $4 \mathrm{~m}$. Both soils have very low shear strength, high compressibility, void ratio, low bearing capacity and high water content [5,9]. However, the peat soil contains more than $75 \%$ with organic contain compared with soft clay that only contain typical homogeneous clay where the soil particles arrangement gives significant differences in soil characteristics. As stated by Kazemian [10], peats have very high in-situ void ratio because of the very compressible and bendable hollow cellular fibres form an open entangled network of particles and the high initial water content. Organic fibre itself can be compressed easily since it's also have voids and moisture content that can be achieved in tertiary consolidation. Thus, this increased the void ratio, compressibility and high water content compared with typical soft clay where affected the density of peat that less compared with density of soft clay. These differences of soil properties explained the soil velocity difference of both soils. 
Table 1 Soil velocity comparison peat and Soft clay with depth

\begin{tabular}{ccc}
\hline \multirow{2}{*}{ Depth $(\mathrm{m})$} & \multicolumn{2}{c}{ P-wave velocity $(\mathrm{m} / \mathrm{s})$} \\
\cline { 2 - 3 } & Peat & Soft Clay \\
\hline 0.0 & 227 & 334 \\
0.5 & 236 & 362 \\
1.0 & 267 & 592 \\
1.5 & 304 & 930 \\
2.0 & 332 & 1112 \\
2.5 & 380 & 1380 \\
3.0 & 445 & 1622 \\
3.5 & 537 & 1661 \\
4.0 & 615 & 1667 \\
\hline
\end{tabular}

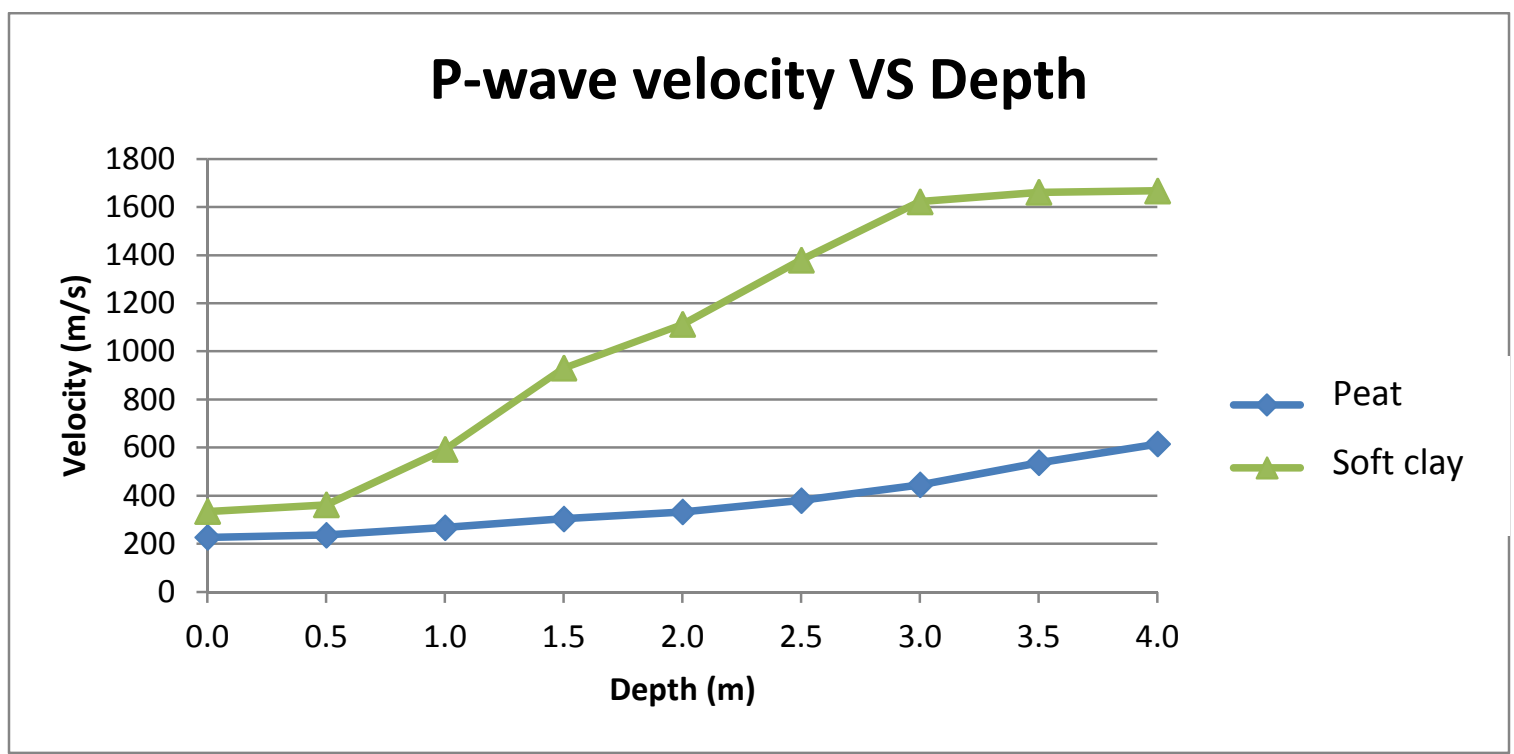

Fig. 5 Difference in soil velocity between peat and soft clay

\section{Conclusion}

Seismic refraction technique has been used to determine soil $\mathrm{p}$-wave velocity of peat and soft clay for comparison. There are significant differences in their velocity due to the organic material that contain in peat soils. These organic contains increase their void ratio, compressibility and water content that affected the density of peat compared with soft clay. Thus, this gives obvious differences with their p-wave velocity due to the existing organic content of peat soils.

\section{Acknowledgement}

The authors would like to thank the University of Tun Hussein Onn, Malaysia, and the Ministry of Education, Malaysia, for their generous granted of this research, FRGS vot. 1224 "Undrained Dynamic Behaviour of Malaysian Peat Soil”. 


\section{Reference}

[1] L. Karlsson. Stratigraphic Boundaries Determined By P-Wave And S-Wave Refraction Surveys In The Gota Alv Valley At Hjartum, Lilla Edet Munipicality. Degree Project For Master Of Sicence, Department of Earth Sciences, University of Gothernborg. (2011).

[2] A. A. Ravindran, and N. Ramanujam. Landslide Investigation Study Using Seismic Refraction and 2D Electrical Resistivity Imaging (ERI) Technique in Ooty, Nilgiri District, Tamilnadu. International Journal of Physical Sciences Vol. 7(49), (2012) p. 6263-6269.

[3] J. M. Reynolds. An Introduction to Applied and Environmental Geophysics. John Wiley \& Sons, Ltd, Chichester, 2nd ed., (2011) p. 712.

[4] T. Dahlin, R. Larsson, V. Leroux, M. Svensson, R. Wisèn: Geophysics Islant Stability Tsut Preparations. Report 62, Swedish Geotechnical Institute, Linköping, (2001) p. 67.

[5] A. Zainorabidin, D. C. Wijeyesekera: Geotechnical Challenges with Malaysian Peat. Proceedings of the AC\&T, (2007) p. 252-261.

[6] J. M. Said: Peat Stabilization with Carbide Lime. Unimas E-Journal of Civil Engineering. Vol 1 :issue 1, 2009.

[7] P.Kolay: Tropical Peat Soil Stabilization using Class F Pond Ash from Coal Fired Power Plant. International Journal of Civil and Environmental Engineering Vol 3:2, (2011).

[8] S. Horpibulsuk, N. Miura and T. S. Nagaraj: Clay-Water/Cement Ratio Identity for Cement Admixed Soft Clays. Journal Of Geotechnical And Geoenvironmental Engineering. Vol 131, (2005) p. 187-192.

[9] M. H. Ho and C.M. Chan: Some Mechanical Properties of Cement Stabilized Malaysian Soft Clay. International Journal of Civil, Architectural, Structural and Construction Engineering. Vol: 5 No:2, (2011) p. $6-13$.

[10] S. Kazemian, K. H. Bujang, A. Prasad and M. Barghchi: A State Of Art Review of Peat: Geotechnical Engineering Perspective. International Journal of the Physical Sciences . Vol. 6(8), (2011) p. 1974-1981 